\title{
LAS HUELLAS DEL PACTO NOVELESCO EN LA CIRCUNCISIÓN DEL SEÑOR SOLO DE JOSÉ LEIVA
}

\author{
Karen Alfaro Ávila
}

\begin{abstract}
In-depth study of the text's narrative voice shows how La Circuncisión is an excellent example of an alienated narrator who is identified with the character. Such tecnique allows La Circuncisión to become an autobiographical piece of fiction which deals with the issue of man submersed in the twentieth century capitalist society.
\end{abstract}

La Circuncisión del Señor Solo de José Leyva, novela española contemporánea, editada en 1972 y galardonada con el premio Biblioteca Breve correspondiente a ese año, permite reseñar la forma de pensar de una generación que se define a partir de una circunstancia histórica de la España contemporánea, la Dictadura Franquista. Este movimiento ofrece, en España, una perspectiva diferente bajo la rúbrica "Nueva Novela". A partir de la misma, se comprende al protagonista enajenado, el cual intenta sobreponerse a un sentimiento de discordancia y resquebrajamiento de sí mismo, como resultado de la multiplicidad de estímulos (ideológicos, políticos, religiosos, etc.) formadores de su conciencia. El relato apunta, en términos de una alegoría, a una serie de mitos sociales, asociados con el progreso, la prosperidad, el poder de consumo, la religión, la sexualidad, propios de un sistema arbitrario como lo era el régimen franquista:

Debe señalarse, sin embargo que sea cual fuere el tipo de mitos sociales a que apunte el mitólogo, el resultado final de su tarea es siempre el descubrimiento de una desoladora realidad oculta tras una barrera de falsas apariencias que ha levantado la clase dominante. El estado totalitario durante los cuarenta años de la dictadura de Franco en las novelas anteriores a 1975, y los amos del capital mundial en las novelas publicadas después de la muerte del dictador (...) (Dolgin 1981:79)

Así, y a raíz de las ideas de Dolgin, el análisis de la problemática del narrador muestra cómo La Circuncisión conforma un magnífico ejemplo de narrador enajenado, donde personaje y narrador se identifican (novela autobiográfica). La estructura de esta obra se caracteriza por su 
experimentalismo, el cual llega a la destrucción de las categorías propias del relato tradicional: la sucesión lineal, orden lógico, respeto a las normas tipográficas, divergencia de identidad, mezcla de pensamientos, etc. Esta dificultad se muestra a través de toda la obra; existe un protagonista que hace uso del procedimiento de replegarse sobre sí mismo, técnica que le permite registrar su vida y su verdad. En relación con la autobiografía Jean Starobinski explica lo siguiente:

(...) no hubiera existido motivo suficiente para la autobiografía sin alguna modificación o transformación (...): conversión, iniciación de una nueva vida, irrupción de la gracia. Si el cambio no hubiera afectado a la existencia del narrador, a este le bastaría con describirse así mismo de una vez por todas, y la única materia cambiante, apropiada para ser objeto de un relato, se reduciría a la serie de acontecimientos exteriores (...) y la persistencia de un narrador en primera persona no hubiera sido ya necesario. Por el contrario, la transformación interior del individuo (...) aporta material para un discurso narrativo que toma el yo por sujeto y objeto. (Starobinski 1970: 71-72)

El desdoblamiento manifiesta la impotencia del protagonista de completar un acto de comunicación. La intensidad con que el sistema lo presiona para que se someta al mandamiento (su circuncisión) y su propia debilidad, lo obligan a refugiarse en su propia imagen.

Las novelas que utilizan la primera persona, tal es el caso de La Circuncisión, acceden más fácilmente a la intimidad. El Yo contribuye a darle una apariencia de verosimilitud al relato, puesto que permite narrar acontecimientos que solo el protagonista podría conocer; al respecto Jorge Chen Sham explica: "La narración autobiográfica permanece auténtica y fidedigna al sujeto" (Chen Sham, por publicar).

El protagonista de La Circuncisión actualiza, con su narración, una circunstancia acaecida en un pasado, su circuncisión, con el propósito de hacer algo que no había hecho en ese momento, rebelarse ante el imperativo social.

\section{Acepciones del término autobiografía}

La crítica literaria hace mención, muy someramente, al origen del término autobiográfico, cuando afirma que Federico Schlegel parece haber sido el primero en utilizar el vocablo (autobiografía) en 1798. Asevera, también, que en inglés se emplea por primera vez hacia 1800 y posteriormente en otras lenguas occidentales. La reciente aparición de la palabra es uno de los argumentos esgrimidos por Philippe Lejeune en su obra L'autobiographie para situar en la segunda mitad del siglo el origen de la autobiografía.

Con respecto al empleo del término, este crítico arguye que es empleado en dos sentidos: el primero, señala que es la vida de un individuo contada por sí mismo; el segundo, corresponde a la obra literaria (novela, poema, tratado filosófico, etc) donde emerge un personaje narrador con la intención de recontar su vida, exponer sus pensamientos o expresar sus sentimientos.

Habida cuenta de lo anterior, cabe señalar que, para el logro de un análisis más fructífero, será necesario restringir el uso del objeto en estudio al de autobiografía literaria, pues, la idea es adecuarse a una situación imaginaria o, mejor dicho, situarse dentro de un pacto de ficcionalidad que, al mismo tiempo, encierra su parte de verdad. 
Las ficciones autobiográficas explotan la posibilidad de narrar en primera persona una historia puramente imaginaria. El yo del relato, en este caso no es asumido "existencialmente" por nadie. En esta clase de textos, el pacto que se establece es el llamado "pacto novelesco" y tiene como tarea instaurar de forma palpable la no identidad del autor y del personaje principal del relato, así como la participación de la comunicación literaria como ficticia.

\section{Huellas del "pacto novelesco" en La Circuncisión del Señor Solo}

En la obra La Circuncisión del Señor Solo se deben señalar dos aspectos, el espacio y el narratario, quienes permitirán afirmar la existencia, en el texto, de este tipo de "pacto novelesco". El primero establece la existencia de un lugar totalmente imaginario en donde se llevan a cabo los acontecimientos, un sitio privado e íntimo. El segundo elemento ofrecerá la oportunidad de considerar que el relato es narrado por un "yo" imaginario e igualmente dirigido a un "tú" ficticio.

\subsection{Narratario}

El narratario es uno de los elementos de la situación narrativa y está situado al mismo nivel que el narrador, pues tanto el primero como el segundo, no corresponden ni al lector real ni al autor:

El narratario -advierte Todorov- no es el lector real, así como el narrador no es el autor y no hay que confundir el papel con el actor que lo asume (Todorov 1975: 78).

En relación con el "auditor-narrativo" de la obra, se puede establecer que en ella se alcanza el nivel intradiegético, pues, a narrador intradiegético-autodiegético, corresponde un narratario intradiegético-autodiegético.

Rara vez, la confidencia no reviste el carácter de intimidad, pues, la misma determina una relación concreta sostenida entre dos, tal como lo manifiesta Carlos Castilla del Pino:

(...) usamos la palabra intimidad a veces para definir lo inaccesible del sujeto, incluso lo indecible, pero también, en ocasiones para el ámbito privado, y desde luego para la relación secreta habida entre dos como es la relación amorosa o la confidencialidad (Castilla 1989: 10).

En el escenario de lo íntimo, afirma el mismo autor, hay dos actores que llevan a cabo una función, el que transmite la confidencia y el que la recibe (Castilla 1989:10). En el caso de la novela en estudio, se trata de un sujeto escindido en dos, es el que habla y el que se oye hablar: 
$<<$ ¿Y es usted la viuda? $>><<$ Vaya engaño; no un caballo, sino el intruso moviendo la carroza $>>$. $<<$ Nos quedamos sin amigo de la forma más estúpida $>$. $<<$ Este cadáver no está muy completo que digamos $>>$. $<<$ Afortunadamente, tuvo la preocupación de circuncidarse antes de morir $>>$. $<<$ Pasando, por pasar a mejor vida $>>$. $<<$ Principio y fin de todas las cosas $>>$. $<<$ Entre ellas, la vida $>$. No quiero seguir escuchando. La suciedad se desprende toda de golpe. La leyenda está acaba. Siento la tentación de firmar mi obra . (Leyva 1972: 72)

Es fácil deducir de esta cita que la intimidad del protagonista se reduce a su desolación; pero, al mismo tiempo, se vale de ésta (intimidad) con el propósito de no ser vencido por la inmensidad representada por los otros.

Parece ser que las novelas que utilizan la primera persona, tal es el caso de La Circuncisión, acceden más fácilmente a la intimidad. El yo contribuye a darle una apariencia de verosimilitud al relato, puesto que permite narrar acontecimientos que sólo el protagonista podría conocer. Además, la narración en primera persona no supone una visión del mundo única, por el contrario, el narrador, el Señor Solo, proyecta su conocimiento presente sobre su actualización del pasado al recrearlo:

La perspectiva de verme atareado de improviso, manoseado y escrutado como si mi cuerpo fuera un objeto, para finalmente sufrir semejante humillación, todo esto en razón de un insólito absurdo (...) (Leyva 1972:18)

Él actualiza con su narración una circunstancia acaecida en un pasado inmediato (su circuncisión), con el propósito de hacer algo que él no había hecho en ese momento, rebelarse ante tal imperativo social, logra su propósito en un primer momento, se niega a ser circuncidado; pero luego cede y comprende su deber, someterse a la disposición, pues, no hay salida.

En relación con el relato en primera persona, Alicia Yllera se manifiesta de la siguiente manera:

El yo contribuye a la mayor verosimilitud de estos relatos, puesto que permite narrar acontecimientos que solo el protagonista podría conocer sin recurrir a un autor omnisciente (juzgado poco verosímil) y descubrir sus más íntimos sentimientos, solo a él asequibles (Yllera 1981:174).

Pareciera ser que el yo permite jugar con la ilusión de que es una historia verdadera, en el sentido de que el criterio más propio y veraz es el propio protagonista narrador.

La novela en primera persona, afirma nuevamente Yllera, es la forma que permitió la plasmación de un universo problemático, no enjuiciado, según un único punto de vista:

(...) un mundo en el que las cosas cobraban valor no por referencias abstractas ajenas al hombre, sino por su interés para una conciencia individual. Es cierto que no todas las novelas en primera persona aprovecharon estas posibilidades y que algunas novelas en tercera persona captaron estas complejas relaciones entre el hombre y el mundo (Quijote), pero la forma aparentemente 
autobiográfica fue el modelo más sencillo para expresar esta diversidad de la experiencia humana. (Yllera 1981: 91)

Por lo tanto, se puede afirmar, entonces, que es a partir del relato en primera persona que el Señor Solo traduce las causas y efectos de la moderna alienación y sobre todo sus manifestaciones humanas en la realidad cotidiana.

\subsection{Espacio}

Genette define el espacio como aquel lugar en donde se llevan a cabo los acontecimientos acaecidos en la historia; sin embargo, es necesario tomar en cuenta sobre todo el espacio donde se realiza el acto comunicativo, pues condiciona las características de la escritura misma.

Antes de introducirse en un análisis del espacio en La Circuncisión, se deben prever las siguientes consideraciones: todo ser humano tiene actuaciones públicas, privadas e íntimas; su distinción no es siempre fácil. Para una mejor comprensión de estos ámbitos (público, privado e íntimo), se hará mención de algunos criterios expresados por Carlos Castilla del Pino en su artículo "Público, privado, íntimo":

Conviene advertir que los que realmente existen son los espacios que, a modo de escenarios, el hombre usa en la representación que constituyen sus actuaciones. Las actuaciones, pues, son públicas, privadas o íntimas no en sí mismas, sino según el espacio en que se desenvuelven. (Castilla 1989: 26)

Esta cita indica, pues, que los espacios en donde se llevan a cabo las actuaciones determinan el carácter de las mismas, ya sean éstas públicas o privadas. Tomando en cuenta estas aseveraciones, el espacio, en La Circuncisión, será el factor posibilitador, para que el protagonista pueda reanudar la conversación (confesión) consigo mismo. Téngase presente que el Señor Solo llega y no sale de su casa, la cual consta de una sola pieza y un único mueble (con diferentes usos).

Pasa al fin a mi casa, observo detenidamente la única pieza de que consta, y me dirijo sin vacilación al solitario mueble de la misma (...) (Leyva 1972: 9)

Esta circunstancia espacial denota el carácter íntimo, del cual el protagonista quiere revestir su plática, replegarse en la intimidad de su hogar, en su lugar privado.

Todo acerca de lo íntimo es incomparable. La intimidad puede inferirse a través de lo que se dice o hace; pero, jamás, se tiene acceso directo, por su intrínseca inobservabilidad. Por eso, la confidencialidad en la obra se basará ante todo en el principio de confianza:

Lo exageras todo, amigo mío, me censuro. La circuncisión sólo puede tener lugar una vez, pero nadie debe circuncidarse por su cuenta. En honor de nuestra vieja amistad me permito hablar conmigo mismo (...) (Leyva 1972: 45)

Debido al carácter íntimo de la confesión del Señor Solo, éste se ve en la necesidad de desdoblarse, para así tener como interlocutor, a él mismo. 
Así que, los acontecimientos acaecidos en La Circuncisión, se desarrollan en dos ámbitos espaciales: uno real (espacio de la enunciación), y otro, el imaginario (espacio propio de la diégesis).

Se definirá cada uno de estos espacios de la siguiente manera:

a. Espacio Real. El ámbito en donde el protagonista lleva a cabo la confesión a su otro "Yo interior". Con el propósito de llegar a un examen exhaustivo del mismo, en la obra La Circuncisión del Señor Solo, es necesario recordar que la condición básica y definidora de la confidencialidad es el pacto de confianza. Sin embargo, para que éste se lleve a cabo con plenitud, el contexto debe reunir propiedades tales que favorezcan el que los actantes puedan cumplir con él sin dificultad. Esto implicaría que, previamente, el protagonista demande de un espacio reducido e íntimo en donde llevar a cabo su auto-confesión en todo su esplendor. ¡Qué mejor lugar que la casa del propio protagonista!, la cual comprende una pequeña habitación, prácticamente ocupada por el extraordinario solio, manejable según su fluir.

Desde este punto de vista, la casa del Señor Solo comprende una sola pieza, en donde existe una silla construida, según cuenta el protagonista, para servir de armario, mesa, lecho, reclinatorio; es decir, está condicionada a las preferencias del usuario:

La utilizo en sus distintas alternativas, de acuerdo al estado de ánimo en que me encuentro (Leyva 1972: 9).

El mueble es lo único de valor que posee el protagonista y ocupa el centro de su habitación; está localizado frente a la ventana, de espaldas a la puerta de acceso.

Al mismo tiempo que el protagonista describe el lugar donde lleva a cabo su auto-confesión, dibuja su mundo interior, un mundo convulso, dominado por la angustia, el miedo, la tristeza, la desazón, la soledad, etc. Expresa un enfrentamiento, una tensión entre dos polos opuestos: la conciencia y el mundo que lo encierra y, por lo tanto, señala el divorcio entre él y el mundo, entre un yo que se afirma y el mundo que lo niega. Es en este ambiente, revestido con características propias de la intimidad, donde reanuda la conversación que desde hace cincuenta años mantiene consigo mismo; un coloquio con carácter de confesión:

Todo está muy tranquilo esta tarde de otoño, nada por tanto me impide reanudar la conversación que desde hace cincuenta años mantengo conmigo mismo (Leyva 1972: 10).

Lo anterior induce a afirmar que la descripción del espacio en La Circuncisión del Señor Solo, amplía la perspectiva de la narración y, al mismo tiempo, adquiere un valor simbólico. Por ejemplo, la descripción de la única pieza de que consta su casa establece una complicidad entre el clima físico y el clima humano. El Señor Solo puede compararse con ese único mueble (silla) que posee su casa, una silla que puede ser manida y adquiere diferentes formas, según los deseos del usuario. De igual manera, él es manipulado por la sociedad, quien le pide obrar de tal o cual manera, dependiendo de sus intereses. Él se figura a sí mismo como un ser amargo y solitario y encuentra tal expresión en la situación de su hogar. 
La soledad, prácticamente, es el único sentimiento que lo invade:

(...) y sus desproporcionadas dimensiones hacen más reducida aún la triste perspectiva del cuarto, prácticamente ocupado por el extraordinario solio (Leyva 1972: 9).

Por un momento, el Señor Solo llega a imaginar que frente al comportamiento obligado, conformado por las convenciones sociales, surge la necesidad de una confesión, cuyo propósito sería la "expresión auténtica del yo", sin trabas, sin códigos sociales. Sin embargo, conforme avanza la confesión a su otro yo, toma conciencia de que ésta lo conducirá, más bien, a subrayar aún más su enajenación, de la cual no está exento ni siquiera su "yo interior".

Entonces, en La Circuncisión no se trata de una confidencia cuya meta sea la liberación del yo "auténtico" del protagonista, sino más bien, la prueba del avasallamiento incluso de lo más íntimo del mismo sujeto:

Todo sin embargo tiene el aire fatídico de nuestro prepucio circuncidado y aún tierno; todo se asemeja a nuestro sexo inseminado (...) (Leyva 1972: 36)

De hecho, todo cambio social produce cambios en el interior de los individuos, incluso en la estructura de sus más hondos sentimientos.

El "yo real" del individuo se evidencia, cuando él mismo reconoce que su papel dentro de la sociedad debe reducirse al de un títere o monigote y no a otro que lo excluya o mantenga fuera del entorno social. Y el protagonista, mediante su confesión, va desmitificando poco a poco la creencia, un tanto romántica, heredada de nuestro pasado, en la que se expresa la existencia de un "yo interior" libre de toda carga social.

(...) la misión que me trae en esta forma comienza con el examen pormenorizado de las gentes, abiertas sobre los enseres, desnudas de cualquier intimidad... (Leyva 1972: 36)

b. Espacio imaginario. Se definirá así, a los diferentes ámbitos espaciales determinados por el fluir de la conciencia del protagonista.

Esta secuencia de imágenes desproporcionadas, que pasan por la conciencia del protagonista, provoca que evolucione dentro del ámbito de una arquitectura complicada, a causa de una yuxtaposición, de lo onírico y de lo real. (Yerro, 1977:106)

Son espacios impregnados de lo escatológico, muchas veces silenciosos, lúgubres, sucios, recargados de una decoración sombría, helada y denigrante; calles sin forma, alcantarillas, escaleras, tejados, paredes, ventanales, botellas, etc. Pareciera ser que esta clase de espacios tiene la intención de encerrar al protagonista en una prisión:

Vago sin vida por las calles movedizas y me detengo frente a lo que creo son los portales de estas casas, el portal común de todas las casa, en cuyos tejados creo advertir la presencia de responsables vigilantes, conscientes vigías destacados con la misión de anunciar los cambios, el avance incontable de las cumbres, el peligro que amenaza con enterrar todo cuanto está en pie. (Leyva 1972: 88) 
Esta serie de desplazamientos inusitados, promovidos por el pensamiento del Señor Solo, van describiendo enteramente su conflicto interior en forma de periplo hacia la interioridad de sí mismo.

Es preciso señalar que, evidentemente, a partir de la descripción del espacio imaginario donde se marca la apertura del protagonista al mundo exterior, es que el Señor Solo traduce su interioridad y asimismo, describe el entorno con sus palabras; es una visión subjetiva del mundo que lo rodea, un mundo decadente y, sobre todo, alienante, del cual no hay salida.

Estas arquitecturas complicadas, escaleras, pasillos, ventanales, alcantarillas, montañas y la percepción de objetos amorfos con los que se relacionan edificios y calles, lo devuelven siempre a su punto de partida, al sin sentido de la vida; dan la sensación de un proceso reiterativo, algo que se traduce indudablemente en la visión mecanizada de la existencia.

Por lo general, y al ser tan puntual en mis entradas y salidas tropiezo con las mismas personas un día y otro; así, la conversación interrumpida ayer es reanudada tras los saludos de rigor y las habituales ceremonias (...) (Leyva 1972: 8)

El espacio real y el imaginario son opresores y dan la imagen de la actitud insignificante de un individuo engullido y devorado por la sociedad.

Una vez concluido el análisis minucioso del narratario y el espacio, elementos determinantes del pacto novelesco, en La Circuncisión, se puede llegar a afirmar lo siguiente:

\section{a. La no identidad entre autor-personaje principal}

El texto evidencia, básicamente, por medio del empleo del pronombre de primera persona "yo", la indudable identidad entre el narrador y el personaje principal, elemento que debe "suponer" toda autobiografía.

YA ESTOY EN LA CALLE, frente a mi casa. Me veo reflejado en los cristales de las ventanas, en todos los cristales de todas las ventanas, inclusive en aquellos a los que no tengo alcance. (Leyva 1972: 7)

La identidad entre el narrador y el personaje principal es reforzada, al inicio de cada capítulo, por la presencia de toda una frase en mayúscula. Es por medio de esta marca evidenciadora, como se puede reafirmar lo siguiente: el relator del texto se asume como un sujeto que revela su propia historia:

ME DOY, AL FIN, LA BIENVENIDA, <<ah, que grata sorpresa>>" (Leyva 1972: 144)

Lógicamente, en el texto se rechaza de manera tajante la posible identificación entre el autor y el personaje principal. En la cobertura del texto, figura el nombre de la persona a quien le pertenece la historia narrada, que lleva como título La circuncisión del Señor Solo, el Señor Solo es el apelativo correspondiente al "héroe" ficticio, narrador del relato, el cual lleva su nombre por título. 
No se debe, pues, de ninguna manera, concluir con la posible identidad entre la nominación del autor, J. Leyva, y la del narrador-personaje principal, Señor Solo. Se advierte, entonces, que los dos apelativos no presentan ninguna relación. El primero (J. Leyva) es la persona real, sujeto material de La circuncisión del Señor Solo y de otros relatos; el segundo es, únicamente, el nombre del personaje ficticio que cuenta un hecho de su vida, dentro de un pacto autobiográfico, creado en la situación comunicativa.

\section{b. La certificación de ficcionalidad}

La comprensión de la narración exige, para Bonati, según lo afirma Pozuelo Ivancos, la entrega a las palabras del narrador:

Este juego culto (de muy seria trascendencia) de proyectar mundos en imagen narrativa necesita, como exigencia, de una cuasi-mecánica de la ilusión, dar crédito irrestringido al narrador. Si no se observa esta regla de juego no hay objeto. Por cierto que esto se finge con conciencia más o menos clara de tal artificio de la fantasía, con distancia irónica. En rigor, una entrega irónica de fe tan limitada solo es posible porque está presidida por la conciencia de lo narrado como ficticio (...), la literatura, en sentido estricto, encuentra en la ficción su posibilidad (...) (Pozuelo 1989: 240)

Por lo tanto, es un hecho irrefutable que la publicación La Circuncisión del Señor Solo bajo el título novela, es prueba convincente para instituir el pacto ficcional, pues, se está ante un relato ficcional autobiográfico en el que se habla de un personaje ficticio, al que le acontecen hechos de ficción en un espacio también imaginario.

Es el Señor Solo, personaje novelístico, quien confiesa su ofuscamiento, al ver tan cercano un hecho vital ineludible, su circuncisión y, en consecuencia, la pérdida de la individualidad.

No se debe obviar, en este apartado, la importancia del alto grado de afectividad que el narrador-protagonista pone en su relato, es decir, del grado de expresividad con el cual se puede develar no solo la coherencia sino su veracidad a lo largo de su enunciado acto de comunicación.

Un narrador omnisciente, según las palabras antes afirmadas, parecería inverosímil, pues vendría a destruir la total soledad del protagonista, todas sus actuaciones solo podían ser conocidas por él. Solo él sabe las consecuencias que puede traer su rebeldía ante las imposiciones sociales; nadie más que él puede develarnos la mezcla de sentimientos, de miedos, rencores, alegrías y dolores que definen el fondo de su carácter.

El protagonista carga así su narración de gran emotividad. Él se encuentra en un momento de su vida, en el cual toma conciencia del papel que debe desempeñar ante la sociedad, el de un ser sin voluntad. Esta opresión de la realidad marca la anagnórisis del Señor Solo y determina que emerja la cruel verdad con tanta vehemencia en el momento en que narra este capítulo tan doloroso en su existencia, por lo cual le imprime ese sello de lo vivido en carne propia:

Mi prepucio al fin humillante es mi propio relato; mi prepucio es una manzana, un pájaro algo triste por las contrariedades. (Leyva 1972: 122) 
Mediante los hechos narrados por este personaje imaginario, se puede observar el predominio de un "yo", un tanto lírico, desde el momento en que se hace patente el influjo de la expresividad; es decir, del alto grado de desasosiego que el hablante (narrador-personaje) externa al hablar consigo mismo. Todos estos acontecimientos relatados a sí mismo se encuentran impregnados de una gran ofuscación, rebeldía y, por último, de resignación.

Este alto grado de lirismo, que el protagonista irradia en los hechos narrados, constituye la base con la que autentifica y da coherencia a su relato.

\subsection{El desdoblamiento del yo y la "imagen especular"}

La transgresión de La Circuncisión, en su nivel narratológico, es tan significativa que los críticos han señalado ese constante replegarse sobre sí mismo ligado a una transgresión de las categorías del relato lineal y lógico:

$\ll$ En grado mayor o menor, todas las novelas de Leyva publicadas hasta la fecha ofrecen unas mismas constantes (...). Estas incluyen una intensa subjetividad manifiesta en el enfoque y la estilística, en una voluntad de innovación visible en la utilización de formas novedosas, divisiones arbitrarias (...) y estructuras experimentales $\gg$ (Pérez 1988: 50)

La circuncisión del Señor Solo supone una singularidad dentro de la clase de autobiografías ficcionales, ya que transgrede su régimen comunicativo. En él se subvierte el circuito de comunicación que enmarca toda práctica autobiográfica, por cuanto emisor y receptor son la misma persona, es decir, narrador y narratario constituyen un solo ente de la misma naturaleza.

El protagonista, el Señor Solo, siente la incapacidad de comunicar sus sentimientos a los demás, lo invade la congoja de que el mundo lo aplaste, de ahí la necesidad de replegarse sobre sí mismo, no cree pertenecer a ninguna parte, viene de nada y va hacia la nada. Este sentimiento lo hace parecer un extraño en su propia tierra hasta el punto de llegar al nihilismo.

Es por ello que surge en él la necesidad de un desdoblamiento: un "yo interior" rebelde que se dirige a un "yo exterior" enajenado, el cual representará la voz de la conciencia; el segundo, en el texto, se encuentra diferenciado del primero por medio de las comillas, como se ha visto:

"Ten la bondad de sentarte", me digo: ¿Sentarme? ¿Y cómo puedo hacerlo? Aquí, aquí hay sitio para todos, en esta maldita silla. "Un poco de calma", me recomiendo. Estoy equivocado: no soy la persona a quien espera; (...) (Leyva 1972: 43)

El desdoblamiento, reproducido por la cita, surge de la conciencia del embelesamiento del protagonista. Es a través de esta doble figuración o por medio de la clarividencia dramática de su otro que aquél dice la verdad.

Es una verdad que el protagonista se ve imposibilitado de comunicar a los demás, por ello, debe encerrarse dentro de un "espacio íntimo", dentro de la propia soledad de un acto comunicativo truncado. 
Efectivamente, el desdoblamiento manifiesta la impotencia del protagonista de completar un acto de comunicación: la intensidad con que el sistema presiona al protagonista, para que se someta al mandamiento (su circuncisión) y su propia debilidad para responder lo obligan a refugiarse en su propia imagen. Por lo tanto, desarticula cualquier funcionalidad del discurso autobiográfico, pues, narra para destruirlo. Se trata de un mecanismo de defensa con el cual el Señor Solo, ante una realidad adversa busca ampararse en sí mismo; de este modo, podrá definirse como lo que "auténticamente" es y no puede dejar de ser un sujeto alienado.

Es posible que mi olvido sea la causa de esta desconfianza, hasta cierto punto justificada. Sin embargo, parece dispuesto a ignorar la trascendencia de mi visita, inclusive valiéndote de una ingenua treta (...) ambos sabemos cuán inútil resulta luchar contra lo inevitable, en esta ocasión el cumplimiento de una orden general (...) (Leyva 1972: 50)

Es por medio de esta doble figuración o "máscara", como lo hace llamar Miguel de Unamuno (citado por Carreño, 1982:19), que el protagonista se da cuenta de la contradicción que el "yo" tiene en su disputa con la sociedad y la cultura en que se halla. La máscara viene a ser nuestra actuación: ese papel el cual nos toca representar y es a través de la misma, que se presenta la conciencia de cada uno.

Desde otro punto de vista, sería la imagen del yo vista en el espejo, llamada por otros "imagen especular" y constituye para el protagonista el primer esbozo en el trazado psíquico del yo. Por medio de la percepción visual del "otro", adquiere el Señor Solo conciencia de su ser. De esta concepción utópica (un "yo" hacia su "otro"), humana y social, surge la conciencia de la propia enajenación:

YA ESTOY EN LA CALLE, frente a mi casa. Me veo reflejado en los cristales de las ventanas, en todos los cristales de todas las ventanas e inclusive en aquellos a los que no tengo alcance (Leyva 1972: 7).

Es a raíz del sentimiento de enajenación que el protagonista concibe el sufrimiento del cual él y los demás son objeto.

Con base en los argumentos antes esgrimidos, se puede afirmar que el eje emotivo a partir del cual el protagonista desarrolla el reconocimiento de su propia imagen es el siguiente: como un sentimiento de huída y búsqueda a la vez fuera de sí mismo y como realización del hombre nuevo a partir del marginado.

Por otro lado, la "imagen especular" le permite al protagonista hacer su propio reconocimiento y al mismo tiempo, comparar o semejar su figura con los demás individuos que lo circundan. El protagonista, por medio de la identificación de su forma con la de los otros, adelanta que él es y será como los otros seres alienados, un ser sin voluntad.

No hay duda de que la transgresión en la novela La circuncisión del Señor Solo radica en su proceso comunicativo. Es un circuito de comunicación imaginario fuera de lo común, aquí se transgrede un orden establecido. El destinatario del mensaje se identifica con la misma persona del destinador y no otra de naturaleza distinta, como es lo clásico en toda escritura autobiográfica. 
Entonces, ¿cuál sería el propósito de tal transgresión? Se puede inferir con base en lo anotado anteriormente, que el propósito de tal transformación discursiva, no es más que la de simular la inestabilidad e incertidumbre del modo de vida contemporánea.

Es imposible eludir que tal rebeldía discursiva señale una forma de concebir el mundo contemporáneo. Una sociedad distorsionada en donde es permanente la dominación ideológica, mediante estereotipos, educación, propaganda, consumismo, religión interpretada en favor de algunos, indiscutiblemente, de los que detentan el poder.

\subsection{El yo escindido y marginal}

Es evidente que el yo es una constante en la novela que vuelve a resurgir con complacencia en la literatura contemporánea. El yo permite jugar, como también lo afirma Yllera, con la ilusión de estar ante una historia verdadera y no ficticia en ese momento (Yllera 1981:164).

No cabe ninguna duda de que algunos novelistas prefirieron la forma autobiográfica, pues, les permitía la plasmación de un universo problemático, un mundo en el que las cosas cobraban valor, por el solo hecho de expresar la diversidad y complejidad de la experiencia humana. Dos ejemplos claros de esta clase de obras son El Lazarillo de Tormes (S. XVI) y La Circuncisión del Señor Solo (J. Leyva, 1972). La primera manifiesta la imposibilidad de que un hombre del bajo pueblo, condenado por la herencia social se eleve jamás al rango de la respetabilidad (Molho, 1984:18); la segunda se instituye como una de las ficciones autobiográficas que patentizan la problemática del hombre contemporáneo, inmerso en la enajenante sociedad capitalista del siglo XX.

Vale la pena enfatizar que lo expresado anteriormente, no autoriza a afirmar que La Circuncisión pudiera pertenecer al género picaresco. De ningún modo se debe postular esto, ya que la misma carece de dos variables, que desde la perspectiva de Maurice Molho, en su artículo “QQué es picarismo?”, serían propios del género picaresco : a) la bajeza del pícaro tiene causa en un linaje vergonzoso (bastardía, vileza de sus padres), b) el pícaro es un deshecho social (delincuente) puesto que vive de robos, mendicidades y sobre todo le obsesiona el dinero (Molho 1984:23).

El protagonista de La Circuncisión no presenta estos dos rasgos, que rotularían a un relato como picaresco. En la novela, de ninguna manera el protagonista se postula como un hombre que viva del robo o de las mendicidades, tampoco plantea su linaje como vergonzoso, no se considera ningún bastardo, ni sus padres se caracterizan por su vileza. Por lo tanto, es mejor plantear la posible afinidad entre estos dos tipos de relatos.

La afinidad entre lo picaresco y La Circuncisión podría radicar en la aparición, en este último relato, de dos de los “temas" básicos del picarismo (Molho 1984: 24):

a. El tratamiento que se le da a la persona YO. Son yoes que poseen el ideal de tener una vida autónoma, sencilla, libre de las convenciones sociales complejas, los cuales desean apartarse de la sociedad para vivir, con el fin de alcanzar en la imaginación esta libertad, por 
ello son considerados seres marginales. El pícaro representa este ideal con actos que le hacían estar fuera de la ley, un cinismo amargo y un vacío moral por lo que había llegado a ser. Al igual que el yo de la picaresca, el Señor Solo también se declara como un ser marginal, desde el momento en que se enfrenta a los falsos valores sociales, aunque al final acabe aceptándolos, pues considera que no hay una posible salida para evadirlos. Él, como otros, está atrapado en los enormes brazos de una sociedad aplastante.

b. A pesar de su deshumanización, el pícaro y el protagonista de La Circuncisión se presentan a sí mismos como hombres capaces de criticar desde su dolorosa lucidez, su persona y su destino, el código moral y social de los grupos dominantes. Precisamente, su marginalidad les permite tal distanciamiento.

Del mismo modo que lo hace el pícaro, su marginalidad le permite al Señor Solo criticar desde fuera una serie de valores alienantes. La siguiente cita lo confirma:

¿Un nuevo estilo de prepucio, señor? Tenemos el mejor surtido, y sobre modelos originales. Prepucios para administrativos, prepucios para políticos, gentes de mundo, sexópatas, deportistas, un inmenso surtido, como decimos. (Leyva 1972: 82)

La cita traduce cómo desde su marginalidad (no querer su circuncisión), el protagonista hace evidente su acorralamiento y su aniquilación, consecuencia de las estructuras propias de una sociedad moderna y, por ende, alienadora. Sería importante señalar que el fenómeno marginal debe ser entendido como una fuerza contraria al poder, tal y como lo concibe Alonso Hernández en su artículo "Marginal y marginado":

(...) resulta evidente que el fenómeno marginal es más fácilmente aprehensible cuando se presenta como fuerza contraria con respecto al poder; independientemente del hecho de que el poder exista precisamente para defender y justificar la norma y viceversa (...) (Alonso 1984:17)

También, es evidente que la condición de marginalidad produce un ser marginado por los otros (ya circuncidados), ya que él mismo se niega a pasar por la prueba, la circuncisión, rito imprescindible para formar parte de la totalidad social y entiéndase el término marginado en el sentido "de lo que se deja de lado, no se tiene en consideración aunque forme parte de la totalidad social" (Alonso 1984:17).

Sin embargo, el fenómeno marginal no dura mucho tiempo para el protagonista, pues el hombre, para conservarse, debe vivir en sociedad (conformarse a partir de sus relaciones con los otros) y por tanto, adaptarse a las disposiciones de ésta.

Al Señor Solo no le queda otra salida sino que aceptar el procedimiento y con ello su alienación para poder pertenecer al grupo social, al respecto, señala Alonso Hernández:

Todo marginalismo se define como situación espacial y como práctica transgresiva con respecto a un tipo de sociedad en un momento determinado. (Alonso 1984: 82) 
Algunos ejemplos que pueden ilustrar lo antes mencionado son los siguientes:

a. El espacio donde se desarrolla el acto comunicativo lo constituye un único cuarto, el cual consta de una sola pieza.

b. El acto de comunicación del protagonista lo realiza consigo mismo.

Así, el fenómeno marginal constituye una práctica transgresiva en la novela, por cuanto, tal y como lo afirma Alonso, entran en contradicción una serie de acciones, con otras valoradas como positivas por el grupo social dominante:

Por práctica transgresiva debe entenderse un conjunto de acciones u omisiones -entendidas éstas también como carencias- que entran en contradicción con equivalentes especulares valorados positivamente por un grupo social dominante en un momento determinado. (Alonso 1980: 113)

A través del fenómeno de marginalidad presente en La Circuncisión, se percibe una inmensa gama de problemas existenciales, producto del avance desmesurado y despiadado de la civilización, circunstancias que en su inmensa mayoría tienden a sumir al hombre en la rutina, la frustración y el aniquilamiento como persona. Este es el caso, claro está, del Señor Solo.

\section{Bibliografía}

Alonso Hernádez, José Luis. 1980. "Didáctica de los marginados”. Imprevue. (1): 113-25.

1990."Marginal y Marginado". Marginalismo S: Actas del 3er Symposium Internacional del Departamento de Español de la Universidad de Groningen, 15, 16 y 17 de octubre de 1984. Groningen: Rijsuniversiteit. 13-8.

Castilla del Pino, Carlos (ed.). 1989. De la intimidad. Barcelona: Editorial Crítica.

Chen S., Jorge. 1996. "El erotismo en la narrativa autobiográfica española: un drama de identidad". Kañina. 19(1). Por aparecer.

Dolgin, Stacey L. 1991. La novela desmitificadora española (1961 - 1982). Barcelona: Editorial Anthropos.

Leyva, J. 1972. La Circuncisión del Señor Solo. Barcelona: Editorial Seix Barral.

Molho, Maurice. 1984. "Qué es picarismo”. Edad de Oro. 2: 127-35.

Pozuelo Yvancos, José María. 1989. Teoría del lenguaje literario. Madrid: Editorial Cátedra. 
Starobinski, Jean. 1970. La relación crítica: Psicoanálisis y literatura. Madrid: Editorial Taurus.

Todorod Tzvetan. 1975. Poética. ¿Qué es el estructuralismo? Buenos Aires: Editorial Losada.

Yllera, Alicia. 1981. "La autobiografía como género renovador de la novela: Lazarillo, Guzmán, Robinson, Moll Flanders, Marianne y Manón. 1616. Anuario de la Sociedad de Literatura Comparada. 4: 163-92. 